\title{
Application of Painting Therapy in the Mental Health Education for College Students
}

\author{
Xinyu Zhang ${ }^{1, a}$, Mengying liu ${ }^{2, b}$ and Wuxuan $\mathrm{Ye}^{3, \mathrm{c}}$ \\ ${ }^{1} 8$, Fochengxi Road, Jiangning District, Nanjing City, Jiangsu Province, China \\ ${ }^{2} 8$, Fochengxi Road, Jiangning District, Nanjing City, Jiangsu Province, China \\ ${ }^{3} 8$, Fochengxi Road, Jiangning District, Nanjing City, Jiangsu Province, China \\ a623887834@qq.com, b1336547853@qq.com, ${ }^{\mathrm{c}} 787505980 @ q q . c o m$
}

\begin{abstract}
Keywords: painting therapy; college students; mental health education; psychological association Abstract. Painting therapy is a treatment with unique advantages that is suitable for college students. This paper introduces the theoretical basis and working mechanism of painting therapy, and analyzes the psychological characteristics of college students and the current situation of psychology education in universities of China. An innovative application of painting therapy to psychological association activities is proposed, which could be a reference in the college psychology education in China.
\end{abstract}

\section{Introduction}

After entering universities, the physiology, psychology and the surroundings of college students changed. The great pressure from study and life may easily lead to their mood swings, and sometimes cause different degrees of psychological problems. Therefore, the mental health education is an important subject which should get the attention and concern of the society. Painting therapy is one of the methods of psychological art therapy with the specific operational treatment and plays an important role in improving mental health and solving college students' psychological problems.

\section{Overview of Painting Therapy}

The Concept and Development of Painting Therapy. Painting is an ancient way of expression which appeared earlier than the emergence of text. Back to the stone-age, our ancestors recorded a number of major events through paintings. The development of western psychology, especially for the modern theory of sub consciousness from Freud and Carl Jung, provides a theoretical basis for the birth of painting therapy. From 1940s, art therapy has become an independent discipline and specialization, and was accepted by the public in early 1960s. Meanwhile, painting therapy, one of the methods of art therapy, was also established and fostered in this period. Art therapy lets participants release feelings and pains which are repressed on the subconscious level through the non-language tool, painting, so as to achieve the effects of relaxation and treatment. The painters can not only show their full thoughts on the square canvas, but also meet the psychological needs in the process of creation.

As one of the main techniques in psychological counseling and treatment, painting therapy has been widely used in western countries. In China, the study of painting therapy from medical, psychological and sociological aspects started from the beginning of the 1990s. After entering the 21 st century, the study of painting therapy in China went deeper and deeper gradually. With the increase of cultural exchanges with foreign countries, better accessibility of electronic resources and growing influence of western psychology theory, painting therapy in China has received more and more attention and acceptance.

The Mechanism of Painting Therapy. Painting therapy can be divided into free painting and the painting under certain regulations. Free painting is fully unrestricted and free from external interference. Visitors can reach their deep inside and draw according to their inner voice which consequently reflects their true emotions. Painting therapy usually consists of the initial stage, the exploration stage and the action stage. The goal of the initial stage is to establish a good relationship with the visitors. Then, 
visitors can strengthen their self-expression during the exploration stage through painting creation. Finally, in the action stage, visitors can continue their further self-expression, set up new goals and establish a target behavior model accordingly.

The deeper people's feelings are, the farther they are away from their sub-consciousness ${ }^{[1]}$. What's more, it is more difficult for them to find reasonable ways to express themselves. The information transmitted by painting therapy is often more considerable and deeper than that of verbal communication, so it is helpful for the people who have difficulties in expressing through language. Painting is one of the tools for emotion expression which can fully reflect information on the subconscious level, because people tend to show few defenses against painting, they would unknowingly express inner conflicts and misery through art creation. Moreover, they can even be released from the hidden or depressed memories and reconstruct their true selves. In the process of painting, people can better understand themselves, further clarify their ideas, visualize and specify their problems in life and finally realize the self-integration in the spiritual world ${ }^{[2]}$. Through painting treatment, people can release bad mood and reflect their problems under the therapist's guide and improve social skills ${ }^{[3]}$. In the treating process, the therapist will listen carefully to the descriptions of the painters about their works. Then, the therapists will analyze the work and treat the painter's meaning with respect. Finally, therapists and painters will discuss together about the symbolic meanings of the picture.

\section{The Current Situation of Undergraduates' Psychology Education}

Psychological Characteristics. Entering university is a turning point of college students' lives. The transformation of roles and the increasing responsibility have brought them great challenges, making them prone to negative emotions. If not adjusted in time, college students will be faced with various psychological problems, including learning anxiety and test pressure, self-perceived barriers, family economic pressures, interpersonal barriers, psychological distress in love and environmental adaptation problems.

The university advocates self-learning. College students are prone to frustration due to the transformation of learning methods and competitive pressure. They may even doubt about their learning ability. Self-cognitive impairment is that college students cannot make proper understanding and evaluation of themselves and have kinds of cognitive bias. College students from poor families bear the huge economic pressure and are prone to inferiority, sensitivity, anxiety and other psychological problems. College students care more about their relationship with others than before, and interpersonal disharmony is more likely to cause mental health problems. With the development of body and mind, college students may also have sexual maturity and love problems. Due to the lack of experience, they cannot correctly handle those problems and arouse psychological distress. The change of the environment is the primary challenge which the freshman have to face. The changes of living habits, climate and differences in diet, lifestyle and health habits make college students anxious and sensitive. The painting therapy can contribute to resolving their negative emotions and dealing with the various psychological problems ${ }^{[4]}$.

The Problems about College Students' Mental Health Education. Mental health education includes psychological consultation, psychological knowledge sharing and psychological crisis intervention. The education mainly have the forms of teachers' psychological counseling, psychological counseling education programs, mental health lectures, and so on. Most students accept psychological consultation, however, only a small proportion of students may go to the psychological consulting room to ask for help. Many students are defensive against psychological counseling, regarding it as a symbol of mental or psychological abnormality. When college students have psychological distress, they prefer to ask for help from their classmates rather than psychological counseling. The current psychological health education still cannot meet the needs of students. Universities need to improve traditional psychological counseling forms and explore more ways which are more acceptable for students and benefit more students. The painting focusing on expressing the 
inner spiritual world has very good acceptability, which could be an effective supplement to the traditional way of mental health education.

\section{Application of Painting Therapy in College Students' Mental Health Education}

Study on Painting Therapy for College Students. Wanjie Tang (2007) developed the college students' painting aesthetic activity model, and found painting aesthetic activities can improve college students' psychological health level ${ }^{[5]}$. Liqun Gong (2008) found painting deepened students understanding of self-treatment, and improved the level of self-acceptance ${ }^{[6]}$.Yuan Tian (2014) discovered painting therapy had significant effects on college students' self-consciousness ${ }^{[7]}$. College students painting aesthetic model has been established, but the theoretical basis is yet to be improved so as to develop a complete system, and the ways of practical application need to be further explored.

Feasibility of Painting Therapy for College Students. Based on the characteristics of painting therapy, it is generally believed that painting therapy is mainly applied to the patients who are unable to speak or do not want to talk, while the curative effect of other methods is poor ${ }^{[8]}$. At present, painting therapy is mainly used for patients with neurological disorders or mental disorders, focusing on exploring the deep depression in the bottom of their hearts ${ }^{[9]}$. With the continuous development of psychological counseling and treatment, researchers more concerned about patients' emotional expression and performance in the treatment process. For relatively "normal" college students, painting therapy has a good adaptability and development prospects. Painting therapy is not limited by the language, age, cognitive abilities and painting skills, and its inherent interest makes it easier to be accepted by college student. Nietzsche said: "Art is life's self-salvation" ${ }^{\text {[10] }}$. Students can learn more about themselves, relieve their psychological stress and complete self-healing by such a relaxing way.

Painting therapy works for not only those special college students who have psychological problems but also moral students. College students can know more about their own psychological condition and take preventive measures to improve resilience when they are in the process of painting creation, which helps them deal with psychological crisis more timely and effectively. College student mental health education should give priority to prevention, and combine prevention and treatment. As a new kind of psychological treatment tool, painting therapy plays a positive role in prevention and treatment of college students' psychological problems.

Application Forms of Painting Therapy for College Students. Although the painting therapy is relatively easy to start, it is still in the theoretical research stage and has not been advocated and put into practice on the large-scale. Cozy and spacious painting room with full range of painting materials are the essential condition of painting therapy, and effective campus promotion is the key to the success application. It is essential to make full use of the advantages of painting therapy in psychological consultation, explore the feasible practical forms in colleges, and popularize the painting therapy in colleges.

As a form of peer counseling, psychological associations developed rapidly in recent years, and almost cover every college. The functions of the psychological association include propagandizing psychological knowledge and ideas, carrying out mental health education activities and providing assistance services, etc. The combination of painting therapy and psychological association is a great innovation in college students' mental health education. It reduces the sense of defense and resistance of college students. Tutoring between peers is more relaxing and natural, which conforms to the characteristics of college students who tend to seek help from their peers when they have psychological problems. By teachers' professional guidance, psychological associations aim to provide students with a healthy way of emotional counseling. Psychological associations can make full use of the supplementary role of painting therapy in psychological counseling. Hohai University has started the preliminary exploration and practices of college painting associations, giving fresh impetus in mental health education for universities. 


\section{Conclusions}

Painting therapy is one of the forms of art therapy, and it is a kind of effective psychological treatment method which has good adaptability and promising perspectives for college students.

The advantages of painting therapy can compensate for the shortcomings of talk therapy, such as reducing the psychological defense of students to psychological counseling, and play a supplementary role in psychological counseling on campus.

Painting therapy can be used in the college psychological association activities, which can take the advantages of peer tutoring, under the guidance of professional psychology teachers. It can help college students to timely and effectively resolve the bad mood and improve their mental health. As a result, the application of painting therapy in the college psychological association is a great innovation in the mental health education in universities.

\section{References}

[1] R. Ammann, in: Healing and Transformation in Sand Play, edited by Open Court Publishing Company, Chicago (1993).

[2] Wenhua Yan, in: Psychological Voiceover, edited by Shanghai Pictorial Publishing House, Shanghai (2003). (In Chinese)

[3] M.S. Hammond, in: The Benefits of Expressive Art Therapy with Socially Outcast, potentially Violent Adolescents, edited by Ursuline College (2001).

[4] Jierui liu: submitted to Journal of Social Psychological Science (2015) (In Chinese).

[5] Wanjie Tang, in: An Experimental Study to the Influence of Drawing Aesthetie Psychothrapy on the Undergraduate with Depressive Symptoms, edited by Xinan University (2007). (In Chinese)

[6] Liqun Gong, in: An Exploration of the Application of Art Therapy in Group Training and Counseling of College Students, edited by East China Normal University (2008). (In Chinese)

[7] Yuan Tian, in: The Effectiveness of Art Therapy in Improving Ego-identity in College Students, edited by Soochow University (2014). (In Chinese)

[8] Jinlin tao: submitted to Journal of Chinese Tissue Engineering Research and Clinical Rehabilitation (2007). (In Chinese)

[9] C.D. Jackson, in: Collaboration between Art Teachers and School Counselors of the Johnson City Elementary Schools to Assist At-risk Students: An Art Experiences Model, edited by D. East Tennessee State University (2003).

[10] Yaobo He: submitted to Journal of Campus Psychology (2012). (In Chinese) 